Article No. 251

DOI: https://doi.org/10.26881/srg.2021.8.07

Artykuł badawczy / Research article

Copyright (c) 2021 SRG and I. Morozova ${ }^{1}$

Citation:

Морозова, И. (2021). Русский предэкзистенциализм: К.Н. Леонтьев. Studia Rossica Gedanensia, 8: 121-131. DOI: https://doi.org/10.26881/srg.2021.8.07

Morozova, I. (2021). Russkij predèkzistencializm: K.N. Leont’ev. Studia Rossica Gedanensia, 8: 121-131.

DOI: https://doi.org/10.26881/srg.2021.8.07

\title{
РУССКИЙ ПРЕДЭКЗИСТЕНЦИАЛИЗМ: К.Н. ЛЕОНТЬЕВ
}

\author{
ИНЕССА MOPO3OBA / INESSA MOROZOVA \\ Национальная академия наук Беларуси / National Academy of Sciences of Belarus \\ Институт философии / Institute of Philosophy \\ Отдел социально-философских и антропологических исследований / \\ Social Philosophy and Anthropological Studies Department \\ ул. Сурганова 1, корп. 2, BY-220072, Минск, Беларусь / Surganova St. 1/2, \\ BY-220072 Minsk, Belarus \\ Corresponding Author e-mail: inesmorozova@bk.ru \\ ORCID: https://orcid.org/0000-0002-3566-331X \\ (получено / received 6.09.2021; принято / accepted 20.09.2021)
}

\section{Abstract \\ Russian pre-existentialism: K.N. Leontyev}

The article presents an analysis of the existential motives in K.N. Leontyev's artistic works, which reflects the transformation of the existential intentions presented in the writer's ideological synthesis. It takes into account the evolution of his thinking, the controversial and extraordinary personality of Leontyev, thus confirming his belonging to the Russian pre-existentialism.

\footnotetext{
1 This is an open-access article distributed under the terms of the Creative Commons Attribution-ShareAlike 4.0 International (CC BY-SA 4.0 https://creativecommons.org/licenses/by-sa/4.0/) which permits use, distribution, and reproduction in any medium, provided that the article is properly cited, the use is non-commercial, and no modifications or adaptations are made. Publisher: University of Gdańsk. Faculty of Language [Wydawca: Uniwersytet Gdański. Wydział Filologiczny]
} 
Keywords: existential motives, aesthetics independent on morality, pre-existentialism, personality, artistic creativity.

\section{Резюме}

В статье представлен анализ экзистенциальных мотивов художественного творчества К.Н. Леонтьева, в котором нашла отражение трансформация экзистенциальных интенций, представленных в мировоззренческом синтезе писателя, с учетом эволюции его мышления, противоречивой и неординарной личности Леонтьева, подтверждающий его принадлежность к русскому предэкзистенциализму.

Ключевые слова: экзистенциальные мотивы, внеморальный эстетизм, предэкзистенциализм, личность, художественное творчество.

К 190-летию со дня рождения К.Н. Леонтьева

На факт экзистенциальности творческого наследия Константина Леонтьева, противоречивого русского философа, публициста, писателя и религиозного деятеля второй половины XIX века, в исследовательской литературе указывалось неоднократно. Н. Бердяев в своей фундаментальной работе Константин Леонтьев: Очерк из истории русской религиозной жизни выделял отдельные экзистенциальные мотивы и проблемы, представленные у Леонтьева, однако не определял терминологически этот круг проблем в границах экзистенциальности (Бердяев 1991). Ю. Иваск в концептуальном исследовании жизни и творчества Леонтьева предпринял попытку выявления точек соприкосновения в эстетических системах русского мыслителя и западноевропейских экзистенциалистов (Иваск 1995). В исследованиях Л. Авдеевой, А. Сивака, А. Королькова экзистенциальные устремления определяются именно характерной особенностью творческого наследия Леонтьева. Более того, Д. Володихин в книге Высокомерный странник. Филособия и жизнь Константина Леонтьева указывает на факт существования целого направления, которое, с авторской точки зрения, следовало бы называть «русским предэкзистенциализмом» (Володихин 2000: 78). К этому направлению относятся имена Р.Ю. Виппера, В.В. Розанова, М.О. Гершензона, но ключевой фигурой, по мнению исследователя, является именно Леонтьев, от которого начинает отсчет русский философский предэкзистенциализм:

(...) К.Н. Леонтьев, в творчестве которого - литературном, философском, публицистическом - русский предэкзистенциализм, во-первых, нашел наивысшее свое проявление и, во-вторых, обрел четкие признаки, отделившие его от других ветвей русской философской традиции (...) (Володихин 2000: 78-79).

Предэкзистенциалистов объединяет целый ряд общих черт: это одинокие мыслители, не вписывающиеся ни в одну философскую традицию в чистом 
виде, противостоящие духовно и интеллектуально определяющему миру, это отрицатели прогресса, губящего духовность; эгалитаризма; усредненности и нивелировки, пошлости и мещанства; это антропологи, а не метафизики, перед которыми центральным вопросом стоит проблема человека, проблема личности.

Экзистенциальные мотивы философского наследия Леонтьева изучены достаточно основательно, в отличие от художественного творчества, в котором нашла отражение трансформация экзистенциальных интенций, представленных в мировоззренческом синтезе писателя. Общим местом в экзистенциальном мироощущении, как известно, является так называемая «пограничная ситуация», отражающая момент субъективного осмысления личного одиночества и противопоставленности миру, вселенной. Леонтьев, в сущности, никогда из этой ситуации не выпадал, на протяжении всей своей жизни оставаясь одиноким мыслителем и художником:

Он человек исключительной судьбы. К. Леонтьев принадлежит к тем замечательным людям, для которых основным двигателем является не потребность дела, служение людям или объективным целям, а потребность разрешить проблему личной судьбы. (...) Он решает объективные вопросы в связи с субъективным вопросом своей судьбы (Бердяев 1991: 151).

Даже если кратко проследить его жизненный путь, то можно убедиться в том, что Леонтьев изначально, не взирая на его многочисленные знакомства с известными людьми, остается несколько в стороне от разных направлений и постоянно испытывает неудовлетворенность от собственного творчества. В 1851 году Леонтьев знакомится с И. Тургеневым, «своим единственным литературным учителем» (Рабкина 1991: 124), которому доверяет свои первые художественные опыты. Тургенев вводит молодого Леонтьева в литературный салон Е. Салиас-де-Турнемир, расширяет круг знакомств самолюбивого юноши, пристально следит за его первыми пробами пера, подвергая критике отдельные положения леонтьевского строя мыслей, предсказывая при этом литературное будущее.

Леонтьев назовет это время «периодом искажения»:

После 52-го года именно, я думаю, на меня нашел период искажения. Меня ничто не удовлетворяло в моем творчестве. Я искал - то каких-то необычайно тонких и глубоких открытий в искусстве, какой-то микроскопической и философской бездонности; то гнался за слишком уж яркой образностью и картинностью. Вкус теоретический у меня развивался; я много читал хорошего тогда в свободные минуты; но творчество положительно дремало (Леонтьев 1914: IX: 28).

В 1863 году он назначен секретарем консульства на о. Крит. Потом последуют Андрианополь, Тульча, Янина, Салоники, где складывается блестящая консульская карьера Леонтьева. Он по-прежнему много пишет. Экзотика Востока, его культура, религия, быт дает Леонтьеву мощный импульс творческого вдохновения, расширяет границы его мироощущения и находит воплощение в художественном опыте. «Восточный» период станет для Леонтьева одним из самых ярких и вдохновляющих моментов жизни. Его интересует все: дипломатия, литература, политика, историософия, культура. Необходимо отметить, что 
он по-прежнему находится в границах экзистенциальной потребности разрешить проблему личной судьбы:

Философия Леонтьева уже по той причине глубоко личностна, что стержнем ее всегда была одна-единственная личность с ее опытом, идеями и переживаниями - личность автора; Леонтьев меньше чем кто бы то ни был в русской философии «перекидывает мостики» к чужому опыту. Он был в высшей степени авто-антропологом (Володихин 2000: 90).

Столь же высок потенциал чувственности, эротизма, реализуемый Леонтьевым в богатом и разнообразном любовном опыте, доминантой которого станет гедонизм. Леонтьев даже находит своеобразное наслаждение, откровенничая об этом со своей женой. Биограф А. Коноплянцев усматривает в эротическом поведении Леонтьева неугасимое стремление к красоте чувственности в многообразии ее проявлений:

Это не был простой пошлый разврат, которому предаются многие и средние, и мелкие люди, здесь был разврат, возведенный в поэзию, это были по своему идеалу те вершины красоты, вечной, сияющей, которые не только недоступны многим другим людям, но они их и не замечают (Коноплянцев 1911: 64).

В эту же пору приобретает законченную форму внеморальный эстетизм Леонтьева, тяготеющий более к западноевропейской, нежели русской романтической традиции, суть которого заключена в вытеснении нравственного критерия эстетическим, универсальным и основополагающим в системе ценностей Леонтьева. Главный критерий совершенства для Леонтьева - красота, а основной закон красоты - разнообразие в единстве. Много позднее, пройдя через глубокую трансформацию мировоззрения и ступив на религиозный путь, побывав неоднократно на Афоне, основательно уяснив от афонских монахов и старцев, из богословской литературы сущность православной аскезы, Леонтьев сохранит и чуткое эстетическое восприятие христианства, именно эстетическое отношение к православному культу как своеобразное синтезированное сочетание первых религиозных впечатлений, сформированных еще в раннем возрасте.

Также неудивительно, что эстетику искусства Леонтьев связывает с отражением эстетики жизни. По мнению Леонтьева, реализм литературы второй половины XIX века вступил в третью стадию, стадию разрушения:

Реализм простой наблюдательности уже потому беднее, проще, что в нем нет автора, нет личности, вдохновения, поэтому он пошлее, демократичнее, доступнее всякому бездарному человеку и пишущему, и читающему. Нынешний объективный, безличный всеобщий реализм есть вторичное смесительное упрощение, последовавшее за теплой объективностью Гете, Вальтер Скота, Диккенса и прежнего Жорж Занда, больше ничего (Леонтьев 1992: 114-115).

К. Долгов, следуя утверждениям предшественников, отмечал, что

Леонтьев представлял собой такой тип писателя, художника, который, о чем бы он ни писал, что бы он ни создавал, все его произведения, всё его творчество всегда было в известной мере и даже преимущественно повествованием о самом себе, о событиях своей собственной жизни, о злоключениях, которые с ним случались или которые ему еще предстояло претерпеть (Долгов, online). 
Существование Леонтьева (до 40 лет) в реальной жизни находилось в границах внеморального эстетизма и романтизма, где нравственный критерий растворялся в эстетическом, усиливая тем самым леонтьевское противостояние социуму. Такая позиция трансформируется в художественном тексте, подчеркивая автобиографический характер героя романа Египетский голубъ:

У меня был свой нравственный критериум, в иных случаях довольно строгий. Он был мой, этот критериум, мой собственный, долгим взаимодействием внимательного ума, доброго сердца и страстной фантазии утвержденной и гордостью взлелеянный. Мне не было нужды до того, был ли он пригоден для остального человечества или нет. Моему тогдашнему нравственному чувству он удовлетворял вполне, и - чего же больше? (...) Я хочу был правым перед высшим судьей моим, перед самим собою! (Леонтьев 1991: 452-453).

Таким образом, индивидуализм в сочетании с эстетизмом постулируют автономность личности, дистанцированность индивида от всех и вся. Смысл жизни не так важен, как поиск самой жизни: и принятие ее:

После первых удач, сообразных с моими идеалами, я полюбил жизнь со всеми ее противоречиями, непримиримыми навеки, и стал считать почти священнодействием мое страстное участие в этой живописной драме земного бытия, которой глубокий смысл мне казался невыразимо таинственным, мистически неразгаданным. Приучая себя к борьбе, я вместе с тем учился как можно сильнее и сознательнее наслаждаться тем, что посылала мне судьба. Немногие умели так, как я умел, восхищаться розами, не забывая ни на миг ту боль, которую причиняли мне тогда же даже и самые мелкие шипы! (Леонтьев 1991: 402).

Осознание драматичности и антиномичности бытия усиливает у Леонтьева эстетическое неприятие прозы семейной жизни, романтический дуализм отвергает экзистенциальное понимание суетной опустошенности брака, о чем пессимистично говорит герой Подлипок:

(...) О, Боже мой! не лучше ли стать схимником или монахом, но монахом твердым, светлым, знающим, чего хочет душа, свободным, прозрачным, как свежий осенний день? (...) Эта светлая одинокая жизнь не лучше ли и душного брака, где должны так трагически мешаться и жалость, и скука, и бедные проблески последней пропадающей любви, и дети, и однообразие? (Леонтьев 1991: 239-240).

Следуя за Вл. Соловьевым и опережая теоретические построения Бердяева, Леонтьев не ставит знака равенства между браком и любовью, брак, с его точки зрения, не является достижением идеальной любви, тем самым лишая ореола романтической и моральной идеализации семейно-брачные отношения: «брак есть духовное таинство, а не достижение сердечного идеала. Последний может легко обмануть, а таинство для верующего человека - все будет таинством» (Леонтьев 2011: 362).

Леонтьев, как и Бердяев, видит в браке прежде всего тяжкий труд и бремя, взаимные обязательства, жестко регламентированные устроением семьи: «брак есть иго, которое должно нести... брак есть разделение труда, тяжкий долг, святой и неизбежный...» (Леонтьев 2011: 51). Обращаясь к семантике слова «супруг», Леонтьев поясняет: «Зигос - по-гречески значит иго. Супруга, супруг - на том же языке называются сизигос. Супруг - в сущности и значит то же: 
со-пряженный, вместе запряженный, как пара волов в ярмо, но мы привыкли употреблять это слово, не вдумываясь в его значение...» (Леонтьев 2011: 51). Сравните у Бердяева: «Семья есть несение тягот и школа жертвенности». «В семье есть тяжесть благоустройства и безопасности, страх будущего, бремя...» (Бердяев 2003: 346). И такая жизненная установка вовсе не вступает в противоречие у Леонтьева с альтруистическими рассуждениями автобиографического героя Ладнева (роман Египетский голубъ), влюбленного в замужнюю женщину:

Я не желал зла ни ей, ни мужу... За что же?... Я вовсе не желал бы узнать, что они живут между собой дурно и в раздоре. Нужно быть негодяем, чтобы радоваться несчастию чужой семьи... Я всегда чтил семью, и супружеский мир казался мне всегда одним из высших благ земной жизни... (Леонтьев 1991: 336).

Но и здесь явлена драматическая ситуация (пограничная), в которой герой остро ощущает свое одиночество и безысходность от невозможности избавления от нахлынувшего чувства любви.

С легкой руки Иваска, создавшего фундаментальное исследование Константин Леонтьев (1831-1891). Жизнь и творчество, в леонтьеведении стало фигурировать понятие «супергерой». Художественная проза Леонтьева станет рассматриваться как целостное образование, структурированное образом супергероя. Иваск исходил из тезиса о том, что всю жизнь Леонтьев говорил «преимущественно о себе, он супергерой собственных писаний, всей своей поэмы жизни» (Иваск 1995: 229). Анализируя специфику поэтики художественной прозы Леонтьева, Иваск последовательно и настойчиво констатирует одну и ту же сентенцию:

Многие «лица» в его повестях, едва появившись, куда-то пропадают и затем появляются на дистанции ста страниц! Но надо знать и помнить: ось, стержень любой леонтьевской композиции - не герои, а один герой - и это всегда новая инкарнация самого автора, и его уже нельзя ни с кем спутать: он всегда ясен - в своем развитии. Так что непрочность архитектурной постройки возмещается монументальностью супергероя, диалектикой его становления, его роста (Иваск 1995: 324).

По мнению Иваска, практически все центральные персонажи произведений Леонтьева являются супергероями. Такой же точки зрения придерживается и современная исследовательница Е. Хрипунова, которая предприняла попытку выяснения многозначных смысловых значений понятия «супергерой». Следуя за Иваском, Хрипунова указывает на то, что супергерой - это, в первую очередь, alter ego автора, художественное воплощение личности писателя, системы его мировоззрения и ценностных установок. Во-вторых, отмечает исследовательница, это герой почти всех произведений Леонтьева, некая постоянная величина. «Частные, «видовые» различия персонажей, обусловленные местным и историческим колоритом, возводится писателем к их родовой константе. В-третьих, категория «супергерой» структурирует повествование, стягивает воедино сюжетные линии» (Хрипунова 2002: 5).

Действительно, все перечисленные смысловые значения категории «супергерой» верны с точки зрения наличия их в образной системе Леонтьева, они адекватны текстологической оформленности. Однако оперирование термином 
«супергерой» применительно к творческой системе Леонтьева представляется не совсем удачным и верным. Художественная реализация образа супергероя предполагает наличие черт, свидетельствующих о достаточно сильном, волевом, уверенном в себе и преуспевающем человеке, самодостаточном и независимом, эгоцентричном, противостоящем социуму, устоявшимся традициям и т. д., то есть, фактически, сверхчеловеке. В исследовательской литературе о Леонтьеве неоднократно указывалось на ницшеанство писателя («ницшеанец до Ницше» (Розанов, Бердяев и др.), на то, что Леонтьев очень близко подошел к идее сверхчеловека (Дж. Клайн 1968).

Можно с уверенностью утверждать, что Леонтьев большую часть своей жизни выстраивал именно в границах эстетики Ф. Ницше, его смело можно назвать носителем концептуальных построений Ницше, писателем, трансформировавшим собственные мировоззренческий и эмпирический уровни в художественном творчестве, герои которого носят в той или иной степени сугубо автобиографический характер. Главное, что сближает и объединяет Леонтьева и Ницше - это эстетическое оправдание мира, так называемый внеморальный эстетизм, упоминаемый ранее, или имморализм.

Концепция внеморального эстетизма ярко представлена в прозе Леонтьева, его герои констатируют весьма безапелляционно:

(...) всею моею нравственною жизнью тогда руководил... кодекс моей собственной гордости, система моей произвольной морали, иногда, может быть, и благородной, но нередко в высшей степени безнравственной. Если я скажу, что я не только думал, но и говорил тогда часто: «Лучший критериум поступков - это что к кому идет», то этим я, кажется, скажу все! (роман Египетский голубь) (Леонтьев 1991: 452).

Придавая универсальный характер эстетическому, Леонтьев совпадает с панэстетизмом Ницше в плане универсальной эстетической оценки. Более того, совпадения идут в декларации социального неравенства, в постулировании критерия неравенства (этой своеобразной «метафизической интуиции об иерархии человеческого бытия»), и именно это определяет эстетическое неприятие мещанской действительности, нивелирования общества, типа среднего человека, столь ярко выраженного как у Ницше, так и у Леонтьева. Безличности и усредненности, господству «среднего» человека противопоставлен у Леонтьева приоритет яркой и самобытной индивидуальности, сильной личности. Такая декларация концептуальных установок персонализма и индивидуализма предвосхищает умонастроения Ницше и переходит в плоскость онтологических координат:

Для меня сильный человек сам по себе, яркое историческое и психологическое явление само по себе дорого... Мне дорог Бисмарк как явление, как характер, как пример многим... Только там много бытовой и всякой поэзии, где много государственной и общественной силы. Государственная сила есть скрытый железный остов, на котором великий художник - история лепит изящные и могучие формы культурной человеческой жизни (Леонтьев 1995: 87).

Поэтому примат эстетического над этическим, декларация эстетического оправдания культа красоты, силы, героического, неравенства и иерархии всех 
форм жизни, индивидуализма и персонализма, эстетическое неприятие мещанства и утилитаризма - все это в совокупности своей является точками соприкосновения в творческих системах двух мыслителей. Безусловно, в мировоззренческом синтезе Леонтьева и в его художественной системе есть целый ряд компонентов, свидетельствующих о наличии философской и эстетической общности с Ницше. Однако было бы слишком необдуманно стремиться утверждать о реализации образа супергероя в художественном творчестве Леонтьева. Так, в романе Египетский голубь главный герой Владимир Ладнев находится в определенной эмоционально-психологической и даже метафизической зависимости от замужней женщины Маши Антониади, в которую он безнадежно влюблен. Он не в силах изменить ситуацию, которая привела бы его к победе, подтверждая наличие именно супергеройства, о котором так настойчиво утверждает Иваск. Необходимость выбора, нахождения самого себя в драматической «пограничной ситуации» в данном случае решается Леонтьевым в духе пессимистического примирения с реалиями, идет простая констатация факта, ничего существенного, радикального Ладнев не предпринимает: «Теперь я хочу одного - забвения, покоя... Безмолвие! беззвучное, бесстрастное, безгласное забвение за морем глубоких снегов... Я больше ничего не ищу. Все прошлое отравлено; все новое мне чуждо» (Леонтьев 1991: 471). Думается, что философия настоящего супергероя звучала бы в иных интонациях и в другой смысловой наполненности.

Иваск, анализируя повесть Исповедь мужа, также видит в центральном персонаже произведения супергероя. Однако герой повести, узнав о смерти любимой жены, не выносит одиночества, его жизнь утратила смысловое наполнение. Пограничная ситуация приобретает трагическое очертание, герой определяет для себя суицидальный вариант ухода. Казалось бы, декларация принципов эстетизма и имморализма должна была бы укрепить позицию мужа в констатируемом Иваском статусе супергеройства, однако для завершенной модели супергероя ему не достает самодостаточности, позволяющей избежать зависимости от другого человека в эмоциональном, психологическом, духовном и иных планах. В данном случае герой-муж попадает в многоуровневую зависимость от собственной жены, внезапная смерть которой усиливает трагическое мировосприятие и бессмысленность собственного существования, не позволяющего продолжить жизненную перспективу одиночества. А путь одиночества - это, как известно, удел сильных, герой же выбирает самоубийство, подписываясь в собственной слабости и перечеркивая тем самым кажущееся супергеройство. И в том, и в другом случае остается тайна, непроясненность мотивированности именно такой жизненной позиции героя, его метафизического выбора, вероятно потому, что Леонтьев никогда не сомневался в простой экзистенциальной истине - «драма жизни нашей со всеми ее тайными и тонкими ощущениями полна мистической неразгаданности» (Грифцов 1995: 313).

А. Корольков, указывая на экзистенциальность творчества Леонтьева, проводит параллель с датским философом Сереном Кьеркегором, признанным предтечей западного экзистенциализма. С точки зрения исследователя, их роднит отсутствие системности в философствовании, а также манера повествова- 
ния от имени полуслитого с автором персонажа (Корольков 1991: 110). Кроме того, Кьеркегор был сторонником просвещенной монархии и противником демократии, что роднит его с установками Леонтьева, а также Кьеркегор полагал, что личностное бытие не сводимо к общественному бытию; оно сугубо индивидуально и неповторимо: «Личность является абсолютом, имеющим свою жизненную цель и задачу в самом себе» (Кьеркегор (b), online). В постулировании идеи персонализма угадываются точки соприкосновения двух мыслителей.

Как известно, Кьеркегора называют рыцарем веры, для которого вера - выше всего. Стоит отметить, что стадией, предшествующей вере, философ называл смирение: «Кто не совершил этого душевного движения, тот не имеет веры» (Кьеркегор (b), online). Леонтьев, ступив на религиозный путь в более зрелом возрасте и пройдя сложный процесс смирения, отстаивал принципы православного аскетико-монашеского и строго церковного христианства, в основе которого определял мотив страха и идею «трансцендентного эгоизма» (личного спасения): «Страх животный унижает как будто нас. Тем лучше - унизимся перед Богом; через это мы нравственно станем выше» (Леонтьев 1993: 319). В такой декларации религиозного пессимизма Леонтьев конгениален Кьеркегору, определявшему человека, никогда не испытывавшего страха, бездуховным и полагавшему, что «тот, кто научился страшиться надлежащим образом, научился высшему» (Кьеркегор 1993: 242).

В работе Наслаждение и долг (Кьеркегор (a), online) датский философ выделил три стадии личности: эстетическую, этическую и религиозную. На первой - эстетической стадии для человека есть единственный смысл жизни - наслаждение. На второй - этической стадии человек руководствуется внутренним долгом - познанием самого себя, выбором и созиданием самого себя. На третьей - религиозной стадии человек уже не подменяет вечное блаженство суррогатом благ конечной земной жизни. Эта теория весьма характерна для личности и творчества Леонтьева, чей жизненный путь представляет две основные стадии (по Кьеркегору) - эстетическую и религиозную, этической стадии как таковой в чистом виде в его судьбе не было, скорее, она была растворена в той или иной степени в эстетической. «В философии он искал выхода для человека и нашел целых два: эстетическое... наслаждение миром и монашески-строгое исповедание христианской веры» (Володихин 2000: 90). И совсем не случайно принято считать, что «Леонтьев взял очень высокую вершину в экзистенциализме, сумев стать выразителем обеих линий - и Киркегардовской, и Ницшеанской, кое в чем даже примирив их иерархическим образом» (Володихин 2000: 108).

\section{Библиография /References}

Berdâev, N.A. (1991). Konstantin Leont'ev: očerk iz istorii russkoj religioznoj žizni. V: N.A. Berdâev o russkoj filosofii. Č. 1. Sverdlovsk: Izdatel'stvo Ural'skogo universiteta: 149-284 [Бердяев, Н.A. (1991). Константин Леонтьев: очерк из истории русской религиозной жизни. В: Н.А. Бердяев о русской философии. Ч. 1. Свердловск: Издательство Уральского университета: 149-284]. 
Berdâev, N.A. (2003). Opyt paradoksal'noj ètiki. Moskva: AST [Бердяев, Н.A. (2003). Onыт napaдоксальной этики. Москва: АСТ].

Dolgov, K.M. (2021). Voschoždenie na Afon. Žyzn' i mirosozercanie Konstantina Leonteva. (Online) http://ksvetu.org/wp-content/uploads/2015/11/text_c1720.pdf (dostup: 25.02.2021) [Долгов, К.М. (2021). Восхождение на Афон. Жизнь и миросозериание Константина Леонтьева. (Online) http://ksvetu.org/wp-content/uploads/2015/11/text_c1720.pdf (доступ: 25.02.2021)].

Grifcov, B.A. (1995). Sud'ba K.N. Leont'eva. V: K.N Leont'ev: Pro et Contra: ličnost' i tvorčestvo K. Leont'eva $v$ ocenke russkih mislitelej $i$ issledovatelej (1891-1917 gg.): antologiâ $v$ 2-h knigah. Kn. 1. Sankt-Peterburg: Izdatel'stvo Russkogo Hristianskogo gumanitarnogo instituta: 294-358 [Грифцов, Б.А. (1995). Судьба К.Н. Леонтьева. В: К.Н. Леонтьев: Pro et Contra: личность и творчество К. Леонтьева в оиенке русских мысслителей и исследователей (1891-1917 г2.): антология в 2-х книгах. Кн. 1. Санкт-Петербург: Издательство Русского Христианского гуманитарного института: 294-358].

Hripunova, E.V. (2002). Proza Konstantina Leont'eva: èvolûciâ, problematika, stil'. Avtoreferat dissertacii na soiskanie učenoj stepeni kandidata filologičeskih nauk. Volgograd [Хрипунова, Е.В. (2002). Проза Константина Леонтьева: эволюиия, проблематика, стиль. Автореферат диссертации на соискание ученой степени кандидата филологических наук. Волгоград].

Ivask, Û.P. (1995). Konstantin Leont'ev (1831-1891). Žizn' i tvorčestvo. V: K.N Leont'ev: Pro et Contra: ličnost' i tvorčestvo K. Leont'eva vocenke russkih myslitelej i issledovatelej (1891-1917 gg.): antologiâ $v$ 2-h knigah. Kn. 2. Sankt-Peterburg: Izdatel'stvo Russkogo Hristianskogo gumanitarnogo instituta: 229-650 [Иваск, Ю.П. (1995). Константин Леонтьев (1831-1891). Жизнь и творчество. В: К.Н. Леонтьев: Pro et Contra: личность и творчество К. Леонтьева в оценке русских мыслителей и исследователей (1891-1917 гг.): антология в 2-х книгах. Кн. 2. СанктПетербург: Издательство Русского Христианского гуманитарного института: 229-650].

K’erkegor, S. (2021a). Naslaždenie u dolg. (Online) https://rusneb.ru/catalog/000199_000009_ 003635757/ (dostup: 15.03.2021) [Кьеркегор, С. (2021a). Наслаждение и долг. (Online) https:// rusneb.ru/catalog/000199_000009_003635757/ (доступ: 15.03.2021)].

K'erkegor, S. (2021b). Strah $i$ trepet. (Online) https://bookree.org/reader?file=1361335 (dostup: 28.05.2021) [Кьеркегор, С. (2021b). Страх и трепет. (Online) https://bookree.org/ reader?file=1361335. (доступ: 28.05.2021)].

Kline G.L. (1968). Religious and anti-religious thought in Russia. (Weil Institute Lectures). Chicago: University of Chicago Press.

Konoplâncev A.M. (1911). Žizn' K.N. Leont'eva v svâzi s razvitiem ego mirosozercaniâ. V: Pamâti K.N. Leonteva: [literaturnyj sbornik]. Sankt-Peterburg: Sirius: 5-136 [Коноплянцев A.M. (1911). Жизнь К.Н. Леонтьева в связи с развитием его миросозериания. В: Памяти К.Н. Леонтьева: [литературный сборник]. Санкт-Петербург: Сириус: 5-136].

Korol'kov, A.A. (1991). Proročestva Konstantina Leont'eva. Sankt-Peterburg: Izdatel'stvo СанктПетербургского государственного университета [Корольков, А.А. (1991). Пророчества Константина Леонтьева. Санкт-Петербург: Издательство Санкт-Петербургского государственного университета].

Leont'ev, K.N. (1914). Sobranie sočinenij: v devâti tomach. T. 9. Moskva: izdanie V.M. Sablina [Лeонтьев, К.Н. (1914). Собрание сочинений: в девяти томах. Т. 9. Москва: издание В.М. Саблина].

Leont'ev, K.N. (1991). Egipetskij golub' roman, povest', vospominaniâ. Moskva: Russkaâ kniga [Лeонтьев, К.Н. (1991). Египетский голубъ: роман, повесть, воспоминания. Москва: Русская книга. 
Leont'ev, K.N. (1992). Zapiski otšel’nika. Moskva: Russkaâ kniga [Леонтьев, К.Н. (1992). Записки отшельника. Москва: Русская книга].

Leont'ev, K.N. (1993). Izbrannye pis'ma 1854-1891. Sankt-Peterburg: Puškinskij fond [Леонтьев, К.Н. (1993). Избранные письма 1854-1891. Санкт-Петербург: Пушкинский фонд].

Leont'ev, K.N. (1995). K.N Leont'ev: Pro et Contra: ličnost' i tvorčestvo K. Leont'eva v ocenke russkih myslitelej $i$ issledovatelej (1891-1917 gg.): antologiâ v 2-h knigah. Kn. 2 Sankt-Peterburg: Izdatel'stvo Russkogo Hristianskogo gumanitarnogo instituta [К.Н. Леонтьев: Pro et Contra: личность и творчество К. Леонтьева в оиенке русских мьслителей и исследователей (1891-1917 г2.): антология в 2-х книгах. Кн. 2. Санкт-Петербург: Издательство Русского Христианского гуманитарного института].

Leont'ev, K.N. (2011). Hram i Cerkov'. Minsk: Izdatel'stvo Belorusskogo Ėkzarhata [Леонтьев, К.Н. (2011). Храм и Церковь. Минск: Издательство Белорусского Экзархата].

Rabkina, N.A. (1991). Literaturnye uroki (Turgenev i Konstantin Leont’ev - istoriâ vzaimootnošenij). Voprosy literatury, 4: 124-132 [Рабкина, Н.А. (1991). Литературные уроки (Тургенев и Константин Леонтьев - история взаимоотношений). Вопросы литературы, 4: 124-132].

Volodihin, D.M. (2000). Vysokomernyj strannik: filosofiâ i žizn’ Konstantina Leontéva. Moskva: Manufaktura [Володихин, Д.М. (2000). Высокомерный странник. философия и жизнь Константина Леонтьева. Москва: Мануфактура].

Competing interests: The author declares that he has no competing interests.

Inessa Morozova is a reviewer in this issue of the journal. 